\title{
Altered Distribution of $\beta$-Catenin, and Its Binding Proteins E-Cadherin and APC, in Ulcerative Colitis-Related Colorectal Cancers
}

Daniela E. Aust, M.D., Jonathan P. Terdiman, M.D., Robert F. Willenbucher, M.D.,

Karen Chew, C.T. (A.S.C.P.), Linda Ferrell, M.D., Carmina Florendo, B.S., Annette Molinaro-Clark, M.A., Gustavo B. Baretton, M.D., Ph.D, Udo Löhrs, M.D., Ph.D, Frederic M. Waldman, M.D., Ph.D

Cancer Center (DA, KC, CF, AC, FW) and Departments of Laboratory Medicine (FW), Medicine (RW, JT), and Pathology (LF), University of California San Francisco, San Francisco, California; and Pathologisches Institut der Ludwig-Maximilians-Universität, München, Germany (GB, UL)

The $\beta$-catenin pathway plays a central role in transcriptional signaling and cell-cell interactions in colonic epithelium. Alterations of the expression of $\beta$-catenin, and its binding partners E-cadherin and the adenomatous polyposis coli protein (APC), are frequent events in sporadic colorectal cancer. Ulcerative colitis (UC)-related cancers originate in a field of chronic inflammation and therefore may have different alterations in the $\beta$-catenin pathway than sporadic cancers. To test this hypothesis, expression and subcellular localization of $\beta$-catenin, E-cadherin, and APC were detected by immunohistochemistry in paraffin sections from $33 \mathrm{UC}$-related and 42 sporadic colorectal cancers. Although $\beta$-catenin and E-cadherin expression were predominantly limited to the lateral cell membrane in normal colonic epithelium, both tumor groups showed an overall shift from membranous to cytoplasmic expression for these proteins. An increase in nuclear localization of $\beta$-catenin and a decrease in cytoplasmic APC expression also were seen in both cancer groups compared with normal epithelium. Abnormal $\beta$-catenin expression was more closely linked to E-cadherin alterations in UC-related cancers than in sporadic cancers. In contrast, abnormal $\beta$-catenin expression was more closely linked to APC alterations in sporadic cancers than in UCrelated cancers. These data suggest that alterations of the $\beta$-catenin pathway are important in both UC-related and sporadic colorectal cancers. However, differences in the expression patterns of $\beta$-catenin, E-cadherin, and APC between UC-

Copyright (C) 2001 by The United States and Canadian Academy of Pathology, Inc.

VOL. 14, NO. 1, P. 29, 2001 Printed in the U.S.A.

Date of acceptance:

Address reprint requests to: Frederic M. Waldman, M.D., Ph.D., UCSF Cancer Center, Box 0808, San Francisco, CA 94143-0808; e-mail: waldman@cc.ucsf.edu; fax: 415-476-8218. related and sporadic colorectal cancers suggest that the specific alterations in this pathway may differ in these two cancer groups.

KEY WORDS: APC, $\beta$-catenin, Colorectal cancer, E-cadherin, Immunohistochemistry, Ulcerative colitis.

Mod Pathol 2001;14(1):29-39

$\beta$-catenin is a multifunctional protein that is involved in cell-cell interaction and transcriptional signaling $(1-5)$. $\beta$-catenin expression is largely regulated by its two major binding partners, E-cadherin on the membrane and the adenomatous polyposis coli (APC) protein in the cytoplasm (6). In normal colonic epithelial cells, $\beta$-catenin is predominantly bound to E-cadherin as part of a cell-cell adhesion complex on the lateral cell membrane. Cytoplasmic $\beta$-catenin levels are regulated by binding to a protein complex consisting of APC, glycogen synthase kinase- $3 \beta$, and axin, followed by ubiquitin/proteasome degradation (7-9).

$\beta$-catenin is thought to play a critical role in sporadic colorectal tumorigenesis (4). Although mutations of $\beta$-catenin itself are infrequent in sporadic tumors, alterations of $\beta$-catenin expression are common and in great part are associated with disturbances in the expression of E-cadherin and APC $(1,2,4,7,10-13)$.

Ulcerative colitis (UC)-related neoplastic progression may be associated with different $\beta$-catenin pathway alterations than sporadic carcinogenesis because of its origin in a field of chronic inflammation. Altered E-cadherin expression has been reported in a small number of UC-related cancers (14-16). Expression patterns of $\beta$-catenin and APC have not yet been studied in UC-related cancers.

The aim of this study was to investigate alterations of the $\beta$-catenin, E-cadherin, and APC path- 
way in UC-related colorectal cancers by defining the expression and subcellular localization of these proteins in a series of UC-related and stagematched sporadic cancers.

\section{MATERIALS AND METHODS}

\section{Clinical Materials}

Thirty-three UC-related cancers were identified from the pathology archives of the University of California, San Francisco (15 cases) and from Munich University (18 cases). All UC patients had a history of longstanding disease ( $>7$ years), and their tumors had arisen from UC-affected colonic mucosa. Forty-two archival sporadic cancers were selected from these two institutions to match for pathologic stage. Staging was done according to criteria established by the Union Internationale Contre le Cancer (17). Sporadic tumors were obtained from patients with no family history of colon cancer and no personal history of inflammatory bowel disease. Normal surgical margins and adjacent normal colonic mucosa from the sporadic colectomy specimens served as normal controls.

\section{Immunohistochemistry}

\section{$\beta$-catenin}

Monoclonal mouse anti-human $\beta$-catenin (Transduction Laboratories, Lexington, $\mathrm{KY}$ ) was used at a dilution of 1:5000 or 1:1000. Five-micrometer sections of the paraffin-embedded, formalin-fixed tissue blocks were pretreated for antigen retrieval by microwaving in $10 \mathrm{~mm}$ citrate buffer (pH 6.0) for 15 minutes at high power. The tissue was then incubated with the primary antibody overnight at $4{ }^{\circ} \mathrm{C}$. Staining was visualized using avidin-biotin complex (Vectastain Elite ABC-Kit, Vector Labs, Burlingame, CA) with 3.3' diaminobenzidine tetrahydrochloride $\left(3,3^{\prime}\right.$-diamino-

TABLE 1. Clinical Characteristics

\begin{tabular}{lcc}
\hline & $\begin{array}{c}\text { UC-Related Cases } \\
(n=33)\end{array}$ & $\begin{array}{c}\text { Sporadic Cases } \\
(n=42)\end{array}$ \\
\hline Male $^{a}$ Age $^{a}$ & $52 \%$ & $52 \%$ \\
Tumor location $^{\text {Right colon }}{ }^{b}$ & $48 \pm 16$ & $68 \pm 13$ \\
Left colon & $39 \%$ & $57 \%$ \\
Rectum & $30 \%$ & $26 \%$ \\
Stage & $30 \%$ & $17 \%$ \\
I & & \\
II & $24 \%$ & $24 \%$ \\
III & $15 \%$ & $21 \%$ \\
IV & $39 \%$ & $33 \%$ \\
Grade & $21 \%$ & $21 \%$ \\
G1 & $3 \%$ & $7 \%$ \\
G2 & $64 \%$ & $71 \%$ \\
G3 & $33 \%$ & $22 \%$ \\
\hline
\end{tabular}

${ }^{a}$ Mean age in years \pm standard deviation.

${ }^{b}$ Proximal to splenic flexure. benzidine), and counterstaining was done with hematoxylin. All stain runs included normal colonic mucosa from both pathology archives as normal controls. A difference in staining intensity between the normal controls from the San Francisco and Munich groups was observed. To match intensities, two antibody concentrations were used (1:1000 for Munich cases, 1:5000 for San Francisco cases). The HeLa cell line was used as a positive control.

\section{E-cadherin}

Monoclonal mouse anti-human E-cadherin (Zymed, South San Francisco, CA) was diluted 1:1000 and incubated for 1 hour at room temperature. Pretreatment, visualization, and counterstaining were as above. A breast cancer case with known loss of E-cadherin expression was used as a positive control.

\section{Adenomatous polyposis coli protein}

Polyclonal rabbit anti-human C-terminal APC (Santa Cruz Biotechnology, Santa Cruz, CA) was used at a dilution of 1:500 and incubated overnight at $4{ }^{\circ} \mathrm{C}$. No microwave pretreatment was used. Visualization and counterstaining were as above. Two colon cancer cell lines (SW480, SW403) with truncating mutations of the APC gene were used as positive controls.

\section{Scoring}

The fraction of tumor cells with positive staining for $\beta$-catenin, E-cadherin, and APC was recorded in deciles. Different subcellular locations were evaluated separately for each antibody. Scoring for nuclear $\beta$-catenin included additional intervals of $\leq 1 \%,>1$ and $\leq 5 \%$, and $>5$ and $\leq 10 \%$ positive cells. The staining intensity for each antibody was recorded as +3 , equally intense as normal; +2 , weaker than normal but distinctly visible at low power; +1 , weaker than normal and only barely visible at low power; and 0 , absent. An average intensity of staining for each antibody in each subcellular location was calculated.

Scoring was done without knowledge of tumor group. Reproducibility of scoring was $>85 \%$ both within and between scorers.

\section{Statistical Analysis}

The mean and standard deviation of percent positivity and intensity were calculated for all the antibodies. Cutoff values for abnormal staining patterns were defined by the mean percentage of stained cells in the normal controls, $\pm 2 \mathrm{SD}$. Because the scoring was done in deciles, the cutoff values were set to the decile closest to the mean \pm 


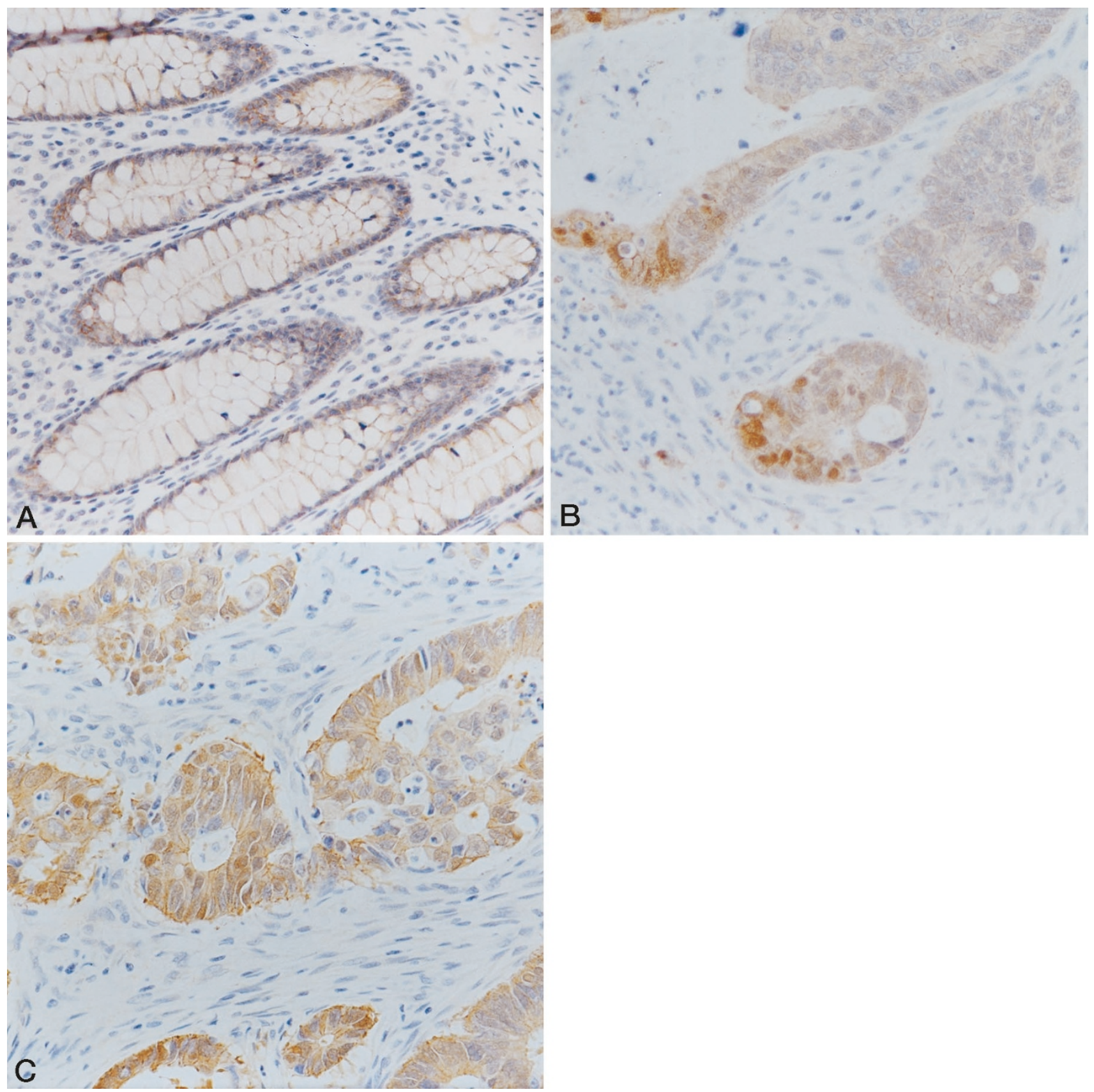

FIGURE 1. Staining of $\beta$-catenin in (A) normal colonic epithelium, (B) ulcerative colitis (UC)-related cancer, and (C) sporadic cancer. Original magnification, $200 \times$. Normal staining is predominantly membranous, whereas tumors show decreased membranous and increased cytoplasmic and nuclear staining. Note that in this UC-related tumor, positive nuclear staining is found predominantly at the invasion front (bottom), whereas the invasion front is not seen in the photo of the sporadic tumor.

2 SD. For $\beta$-catenin, the cutoff values for abnormal staining were $\leq 90 \%$ for membranous staining, $>30 \%$ for cytoplasmic staining, and $>1 \%$ for nuclear staining. For E-cadherin, the cutoff values were $\leq 90 \%$ for membranous staining and $>30 \%$ for cytoplasmic staining. For APC, the cutoff value was $\leq 50 \%$. At least 25 normal controls were assessed for each antibody. Comparison between normal controls and the two tumor groups as well as between the two tumor groups were made using the nonparametric Fisher's exact test.

\section{RESULTS}

Immunohistochemical staining for $\beta$-catenin, E-cadherin, and APC was performed on 33 UCrelated and 42 sporadic colorectal cancers to identify the specific expression pattern of these proteins in UC-related cancers and to define differences in the expression pattern between the two groups. The two tumor groups showed a similar distribution of stage and grade (Table 1). The patients in the UCrelated group were younger and were more likely to 

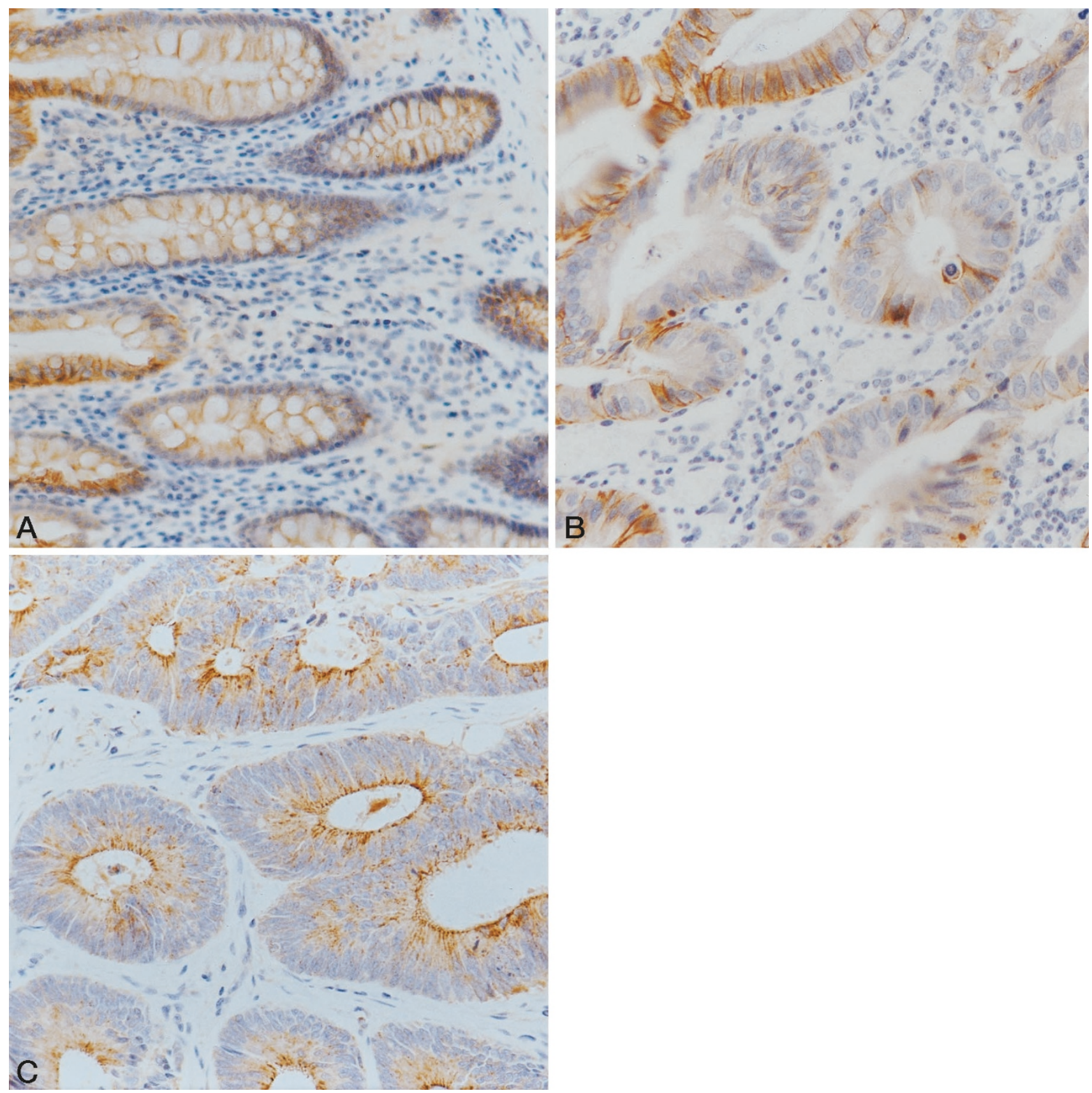

FIGURE 2. Staining of E-cadherin in (A) normal colonic epithelium, (B) ulcerative colitis-related cancer, and (C) sporadic cancer. Original magnification, $200 \times$. Normal staining is predominantly membranous, whereas tumors show decreased membranous and increased cytoplasmic staining.

have left-sided tumors than were those in the sporadic group.

\section{$\beta$-Catenin Expression}

\section{Normal colonic mucosa}

$\beta$-catenin staining was seen predominantly at the lateral membrane of normal colonic mucosa (Fig. 1). Cytoplasmic staining was observed adjacent to the lateral cell borders of apical colonocytes. Nuclear expression of $\beta$-catenin was present in rare basal colonocytes in 4 of 27 normal samples (Fig. 4,
Table 2). Cutoff values for abnormal staining (mean $\pm 2 \mathrm{SD}$ ) were calculated as membranous staining in $\leq 90 \%$ of cells, cytoplasmic staining in $>30 \%$ of cells, and nuclear staining in $>1 \%$ of cells.

\section{UC-related cancers}

The fraction of cells showing membranous $\beta$-catenin staining was significantly lower in UCrelated cancers than in normal colonic mucosa, as was their staining intensity (Table 2). Membranous expression was abnormal in $79 \%$ of the UC-related tumors (Table 3 ). The fraction of cells showing cy- 


\begin{tabular}{|c|c|c|c|c|}
\hline & \multicolumn{4}{|c|}{ Mean Percentage of Stained Cells } \\
\hline & Normal Mucosa & UC-Related $^{b}$ & Sporadic $^{b}$ & UC vs. Sporadic \\
\hline \multicolumn{5}{|l|}{$\beta$-catenin } \\
\hline Membranous & $100 \pm 0^{a}$ & $\begin{aligned} 63 & \pm 30 \\
P & <0.001\end{aligned}$ & $\begin{aligned} 55 & \pm 33 \\
P & <0.001\end{aligned}$ & $\mathrm{NS}^{c}$ \\
\hline Cytoplasmic & $12 \pm 4.1$ & $\begin{aligned} 76 & \pm 27 \\
P & <0.001\end{aligned}$ & $\begin{aligned} 86 & \pm 17 \\
P & <0.001\end{aligned}$ & NS \\
\hline Nuclear & $0.8 \pm 1.9$ & $\begin{array}{l}4 \pm 5 \\
P=0.006\end{array}$ & $\begin{aligned} 10 & \pm 12 \\
P & <0.001\end{aligned}$ & $P=0.0056$ \\
\hline \multicolumn{5}{|l|}{ E-cadherin } \\
\hline Membranous & $100 \pm 0$ & $\begin{aligned} 65 & \pm 25 \\
P & <0.001\end{aligned}$ & $\begin{array}{l}81 \pm 22 \\
P<0.001\end{array}$ & $P=0.004$ \\
\hline Cytoplasmic & $12 \pm 4.4$ & $\begin{aligned} 31 & \pm 35.7 \\
P & =0.008\end{aligned}$ & $\begin{aligned} 60 & \pm 34 \\
P & <0.001\end{aligned}$ & $P=0.001$ \\
\hline \multicolumn{5}{|l|}{ APC } \\
\hline Cytoplasmic & $72 \pm 5$ & $\begin{aligned} 33 & \pm 30 \\
P & <0.001\end{aligned}$ & $\begin{aligned} 25 & \pm 24 \\
P & <0.001\end{aligned}$ & NS \\
\hline
\end{tabular}

${ }^{a}$ Mean percentage \pm standard deviation.

${ }^{b}$ p-value when compared with normal mucosa.

${ }^{c}$ Not significant.

toplasmic staining was increased, as was their staining intensity. Cytoplasmic expression of $\beta$-catenin was above normal in $88 \%$ of the UCrelated tumors. The fraction of cells with nuclear $\beta$-catenin staining was also increased in UC-related tumors, as was their staining intensity. Increased nuclear staining was observed in $48 \%$ of the UCrelated cancers. Cells with nuclear $\beta$-catenin expression were predominantly located in clusters along the invasion front of the tumor.

\section{Sporadic cancers}

The fraction of cells showing membranous $\beta$-catenin staining was decreased in sporadic cancers, as was their staining intensity. Eighty-three percent of the sporadic cancers showed abnormal membranous expression. The frequency and intensity of cytoplasmic staining was increased, with $95 \%$ of the sporadic tumors showing abnormal cytoplasmic $\beta$-catenin expression. Nuclear expression of $\beta$-catenin was also increased with respect to frequency and intensity, with $81 \%$ of the tumors showing abnormal nuclear expression. Cells with nuclear $\beta$-catenin expression were predominantly

TABLE 3. Frequency of Abnormal Staining ${ }^{a}$

\begin{tabular}{lccc}
\hline & UC-Related & Sporadic & \\
\hline$\beta$-catenin & & & \\
Membranous & 79 & 83 & $\mathrm{NS}^{b}$ \\
Cytoplasmic & 88 & 95 & $\mathrm{NS}$ \\
Nuclear & 48 & 81 & $P=0.003$ \\
E-cadherin & & & \\
Membranous & 94 & 60 & $P=0.001$ \\
Cytoplasmic & 30 & 71 & $P<0.001$ \\
APC & & & NS \\
Cytoplasmic & 76 & 88 &
\end{tabular}

${ }^{a}$ See text for cutpoints used to define abnormality, values are $\%$ abnormal cases.

${ }^{b}$ Difference between UC-related and sporadic cancers. located in clusters along the invasion front of the tumors.

\section{Comparison of UC-related and sporadic tumors}

Both tumor groups showed a similar pattern of decreased membranous and increased cytoplasmic expression of $\beta$-catenin. However, nuclear expression of $\beta$-catenin was less frequent and less intense in UC-related than sporadic tumors. Abnormal nuclear staining was seen in $48 \%$ of UC-related versus $81 \%$ of sporadic cancers $(P<0.01$, Table 3$)$.

\section{E-Cadherin Expression}

\section{Normal colonic mucosa}

Normal colonic mucosa showed continuous membranous expression of E-cadherin along the lateral cell borders in $100 \%$ of cells (Fig. 2). Cytoplasmic E-cadherin expression was seen in apical colonocytes. Cutoff values for abnormal staining (mean \pm 2 SD) were calculated as membranous staining in $\leq 90 \%$ of cells and as cytoplasmic staining in $>30 \%$ of cells.

\section{UC-related cancers}

The fraction of cells showing membranous E-cadherin staining was significantly lower in UCrelated cancers than in normal colonic mucosa (Fig. 5; Table 2), as was their staining intensity. Membranous staining was disrupted in $67 \%$ of the tumors. Ninety-four percent of the UC-related cancers showed abnormal membranous E-cadherin expression (Table 3). The fraction of cells showing cytoplasmic staining was increased, as was their staining intensity. Abnormal cytoplasmic E-cadherin expression was seen in $30 \%$ of the UC-related cancers. 


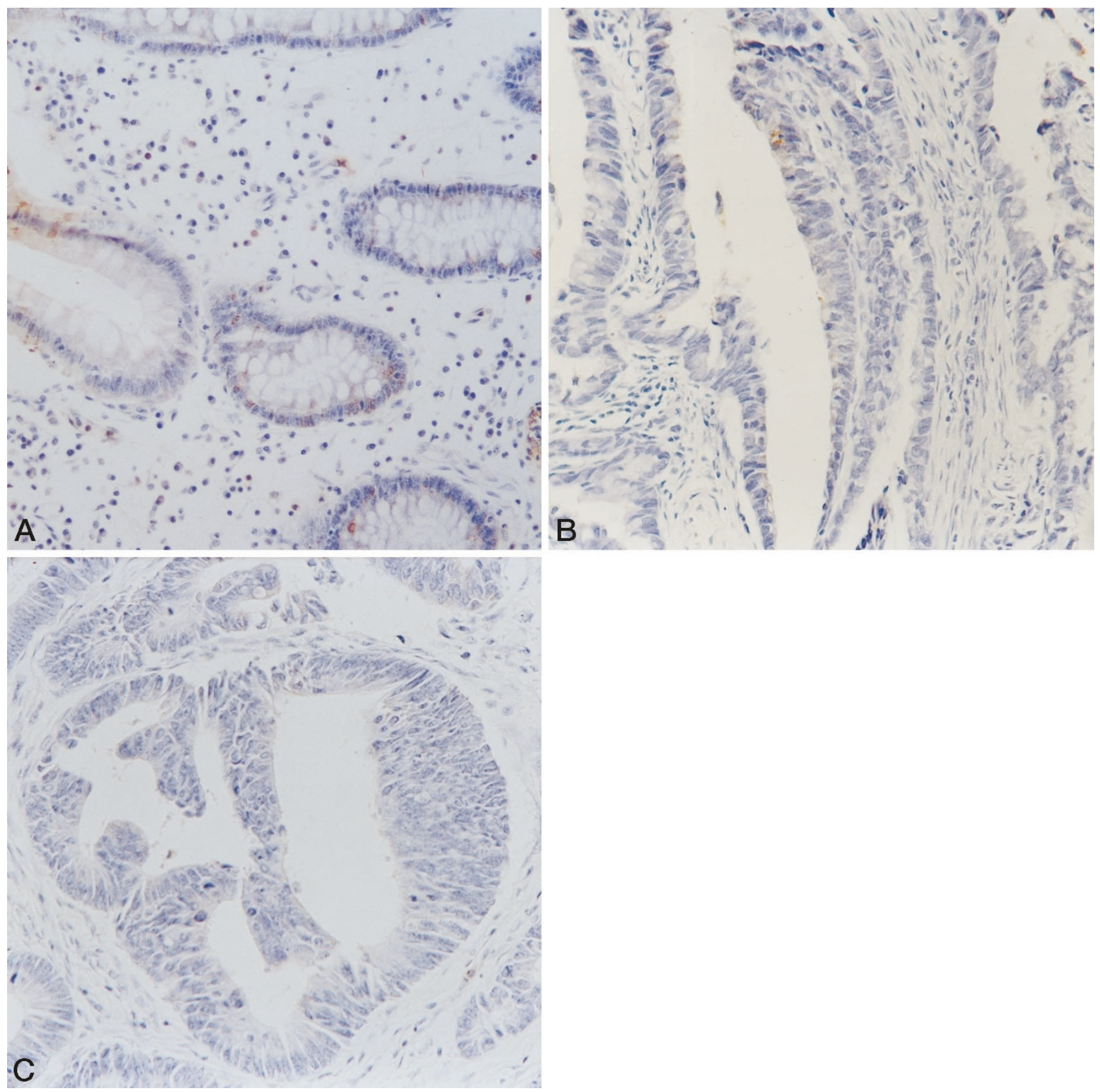

FIGURE 3. Staining of APC in (A) normal colonic epithelium, (B) ulcerative colitis-related cancer, and (C) sporadic cancer. Original magnification, 200×. Normal epithelium demonstrates a gradient of cytoplasmic staining from basal to surface layers. Tumors show decreased frequency and intensity of staining.

\section{Sporadic cancers}

The frequency and intensity of membranous E-cadherin staining was decreased, with $60 \%$ of the sporadic tumors showing abnormal membranous expression, although a disrupted membranous staining pattern was seen in only 33\% of the cases. Cytoplasmic expression of E-cadherin was increased with respect to both frequency and intensity, with $71 \%$ of the sporadic cancers being abnormal.

\section{Comparison of UC-related and sporadic tumors}

Both tumor groups showed an overall pattern of decreased membranous and increased cyto- plasmic staining for E-cadherin. Membranous E-cadherin expression was more often abnormal in UC-related tumors than in sporadic tumors $(P$ $<0.01$, Table 3 ). In contrast, cytoplasmic expression was less often abnormal in UC-related tumors $(P<0.01)$.

\section{APC Expression}

\section{Normal colonic mucosa}

APC showed a gradient of cytoplasmic staining throughout the colonic crypt. Basal cells were generally negative for APC, with increasing proportion 
and intensity of staining toward the surface and $100 \%$ positivity at the luminal surface (Fig. 3). The average percentage of stained cells was $72 \%$ (Fig. 6; Table 2). A cutoff value for abnormal staining (mean $\pm 2 \mathrm{SD}$ ) were calculated as $\leq 50 \%$ cells stained. No membranous or nuclear staining was seen.
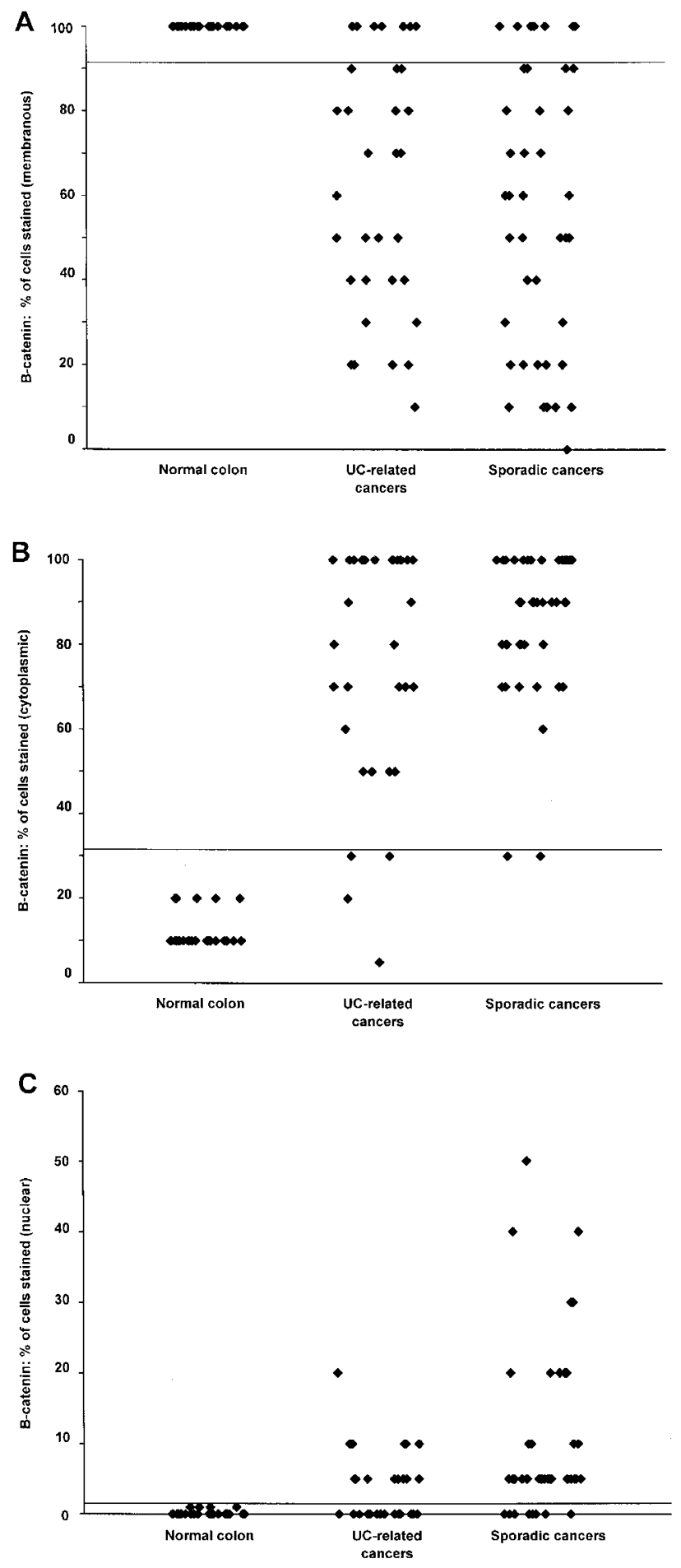

FIGURE 4. $\beta$-catenin staining in normal colonic mucosa, ulcerative colitis-related cancer, and sporadic cancer. Each dot represents one case. A, membranous staining. B, cytoplasmic staining. C, nuclear staining. Horizontal line separates normal and abnormal cases.
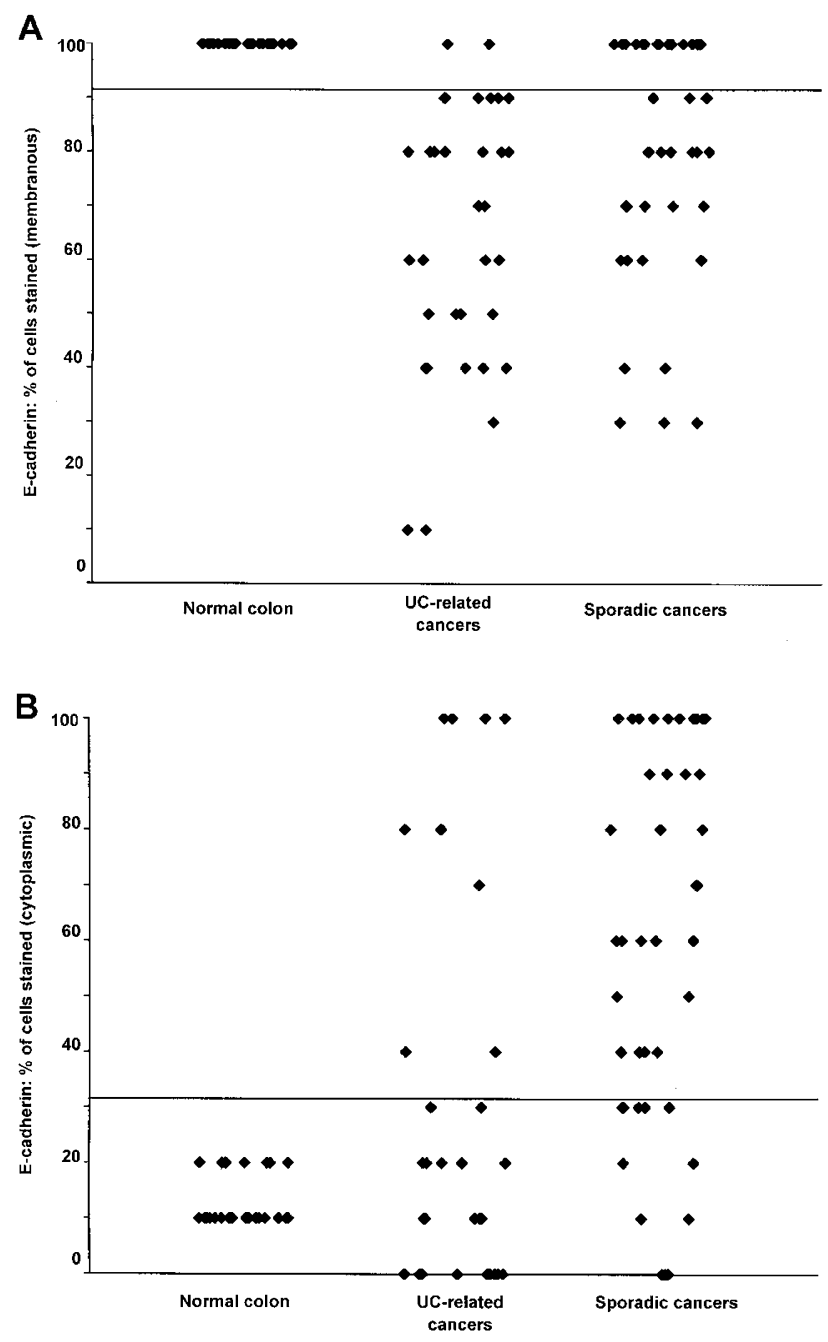

FIGURE 5. E-cadherin staining in normal colonic mucosa, ulcerative colitis-related cancer, and sporadic cancer. A, membranous staining. B cytoplasmic staining.

\section{UC-related cancers}

The fraction of cells showing cytoplasmic APC staining was significantly lower in UC-related cancers than in normal colonic mucosa, as was their staining intensity. Seventy-six percent of the UCrelated tumors showed abnormal APC expression (Table 3).

\section{Sporadic cancers}

Cytoplasmic APC staining was decreased in frequency and intensity in the sporadic tumors, with $88 \%$ of the sporadic cancers showing abnormal staining.

\section{Comparison of UC-related and sporadic tumors}

The difference in the staining pattern for APC between the two groups was not significant.

\section{$\beta$-Catenin, E-Cadherin, and APC Associations}

If the pool of free cytoplasmic $\beta$-catenin is regulated by its binding partners E-cadherin and APC, 


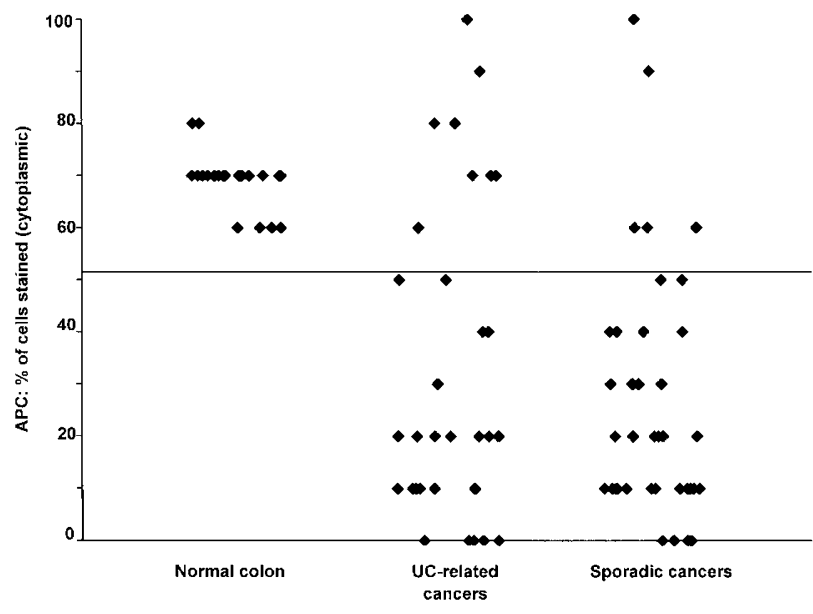

FIGURE 6. Staining of cytoplasmic adenomatous polyposis coli protein in normal colonic mucosa, ulcerative colitis-related cancer, and sporadic cancer.

then abnormal membranous E-cadherin expression or abnormal APC expression should result in abnormal cytoplasmic $\beta$-catenin expression. If the increase in the cytoplasmic pool of $\beta$-catenin and/or the lack of functioning APC is responsible for increased nuclear trafficking of $\beta$-catenin, then abnormal cytoplasmic $\beta$-catenin and/or abnormal APC expression should result in abnormal nuclear $\beta$-catenin expression. To test whether our immunohistological data could provide support for these pathway associations, the associations among $\beta$-catenin, E-cadherin, and APC staining were investigated.

The association between abnormal E-cadherin membranous staining and abnormal $\beta$-catenin cytoplasmic staining was stronger in UC-related cancers than in sporadic cancers $(P=0.038$ for a difference between the two tumor groups, Table 4). This was not true for the association between abnormal cytoplasmic E-cadherin staining and abnormal cytoplasmic $\beta$-catenin staining. In contrast, a smaller number of UC-related cancers, compared with the sporadic tumors, demonstrated abnormal staining of both APC and cytoplasmic $\beta$-catenin $(P$ $=0.161$ a the difference between the two tumor groups, Table 5). In the UC-related cancers, no association was found between the abnormal stain-

TABLE 4. Membranous E-Cadherin versus Cytoplasmic $\beta$-Catenin Staining

\begin{tabular}{|c|c|c|c|c|}
\hline & \multicolumn{4}{|c|}{$\beta$-Cat Cytoplasmic ${ }^{a}$} \\
\hline & \multicolumn{2}{|c|}{ UC-Related } & \multicolumn{2}{|c|}{ Sporadic $^{b}$} \\
\hline & Normal & Abnormal & Normal & Abnormal \\
\hline \multicolumn{5}{|c|}{ E-cadherin membranous } \\
\hline Normal & 0 & 6 & 2 & 38 \\
\hline Abnormal & 12 & 82 & 2 & 57 \\
\hline
\end{tabular}

TABLE 5. APC versus Cytoplasmic $\beta$-Catenin Staining

\begin{tabular}{|c|c|c|c|c|}
\hline & \multicolumn{4}{|c|}{$\beta$-Cat Cytoplasmic ${ }^{a}$} \\
\hline & \multicolumn{2}{|c|}{ UC-Related } & \multicolumn{2}{|c|}{ Sporadic $^{b}$} \\
\hline & Normal & Abnormal & Normal & Abnormal \\
\hline \multicolumn{5}{|l|}{ APC } \\
\hline Normal & 3 & 21 & 0 & 12 \\
\hline Abnormal & 9 & 67 & 5 & 83 \\
\hline
\end{tabular}

ing of $\beta$-catenin in the cytoplasm and nucleus, whereas such an association was present in the sporadic cancers $(P=0.003$ for a difference between the two tumor groups, Table 6). Further, in the UC-related cancers, no association was found between abnormal APC staining and nuclear $\beta$-catenin staining, whereas again this association was present in the sporadic cancers $(P=0.024$ for a difference between the two tumor groups, Table 7).

\section{DISCUSSION}

$\beta$-catenin plays a major role in cadherin mediated cell-cell adhesion as well as in transcriptional signaling in colonic epithelium. Alterations of $\beta$-catenin expression are likely to affect both of these functions (18). $\beta$-catenin expression is frequently altered in sporadic colorectal cancers $(1,2$, $7,11,19)$, whereas very little is known about its expression in UC-related cancers. In this study, immunohistochemistry was used to define the expression of $\beta$-catenin, and its two binding partners E-cadherin and APC, in UC-related colorectal cancers.

Immunohistochemical evaluation offers several advantages, including the ability to work with small archival tumor specimens and the ability to detect small populations of cells with altered protein expression. However, we are mindful of the limitations of this approach. Alterations in immunostaining are neither completely sensitive nor specific for alterations in protein expression. Changes in antigen availability may occur because of posttranslational modification or other intracellular processes. Further, immunohistochemistry provides no direct information on the precise mechanism of altered

TABLE 6. Cytoplasmic versus Nuclear $\beta$-Catenin Staining

\begin{tabular}{|c|c|c|c|c|}
\hline & \multicolumn{4}{|c|}{$\beta$-Cat Nuclear ${ }^{a}$} \\
\hline & \multicolumn{2}{|c|}{ UC-Related } & \multicolumn{2}{|c|}{ Sporadic $^{b}$} \\
\hline & Normal & Abnormal & Normal & Abnormal \\
\hline \multicolumn{5}{|c|}{$\beta$-cat cytoplasmic } \\
\hline Normal & 6 & 6 & 2 & 2 \\
\hline Abnormal & 45 & 42 & 17 & 79 \\
\hline
\end{tabular}


TABLE 7. APC versus Nuclear $\beta$-Catenin Staining

\begin{tabular}{|c|c|c|c|c|}
\hline & \multicolumn{4}{|c|}{$\beta$-Cat Nuclear ${ }^{a}$} \\
\hline & \multicolumn{2}{|c|}{ UC-Related } & \multicolumn{2}{|c|}{ Sporadic $^{b}$} \\
\hline & Normal & Abnormal & Normal & Abnormal \\
\hline \multicolumn{5}{|l|}{ APC } \\
\hline Normal & 12 & 12 & 2 & 10 \\
\hline Abnormal & 39 & 36 & 17 & 71 \\
\hline
\end{tabular}

protein function. Follow-up studies examining the genetic and epigenetic events underlying the alterations detected by immunostaining are required.

Similar alterations of $\beta$-catenin staining were seen in the UC-related and sporadic colorectal cancers. A decrease in membranous $\beta$-catenin expression and increases in cytoplasmic and nuclear $\beta$-catenin expression were observed in the UCrelated cancers, similar to that seen elsewhere in sporadic colorectal cancers $(1,11)$. The increase in nuclear expression, however, was less frequent in the UC-related (48\%) than in the sporadic tumors (81\%).

The relative lack of $\beta$-catenin expression in the nuclei of UC-related tumors and the absent link between cytoplasmic and nuclear expression may indicate that $\beta$-catenin-mediated transcriptional signaling is less important in UC-related than in sporadic cancers. Alternatively, the relative absence of nuclear $\beta$-catenin expression may be due to additional alterations of downstream proteins in UCrelated cancers, such as Tcf/Lef transcription factors, or the nuclear stability of the protein may differ from that in sporadic tumors.

Mutations of the $\beta$-catenin gene are rare in sporadic colorectal cancers and therefore are not the cause of altered $\beta$-catenin expression in these tumors $(4,10,20)$. Mutations in Exon 3 of the $\beta$-catenin gene were also not detected in this set of UC-related cancers (data not shown). Alterations in $\beta$-catenin protein expression and subcellular localization in both tumor groups are therefore more likely due to alterations of one of $\beta$-catenin's binding partners, E-cadherin or APC.

A substantial decrease in membranous E-cadherin expression, with a concomitant increase in cytoplasmic E-cadherin expression, was observed in both UCrelated and sporadic colorectal cancers. Disturbances of E-cadherin mediated cell-cell adhesion with decreased membranous and increased cytoplasmic expression of E-cadherin have been previously described in sporadic colorectal cancers $(2,21,22)$ and in UC-related cancer (14). The primary mechanism proposed for loss of E-cadherin expression in sporadic colorectal cancer is gene silencing by hypermethylation of the promotor region (23-27). Cytoplasmic redistribution of E-cadherin has been reported to be caused by the down-regulation of its tyrosine phosphorylation (28). The mechanism of E-cadherin alteration in UC-related cancers remains unclear. Allelic loss of the E-cadherin locus (16q22.1) is an infrequent event in UC-related cancers $(14,19)$ and cannot account for alterations in protein expression.

A more pronounced decrease in membranous E-cadherin expression and a higher frequency of disrupted membranous staining was observed in UCrelated than in sporadic tumors. Also, the linkage between membranous E-cadherin and cytoplasmic $\beta$-catenin expression was stronger in UC-related than sporadic cancers. This suggests that E-cadherin is driving the alteration of $\beta$-catenin expression in UCrelated cancers. The decrease in membranous E-cadherin may be an early event in UC-related tumorigenesis because decreased membranous E-cadherin expression also can be detected in UCaffected, nondysplastic colonic mucosa $(15,16)$. The increase in cytoplasmic E-cadherin expression, however, was less pronounced in UC-related tumors.

APC expression was decreased in $76 \%$ of the UCrelated cancers and in $88 \%$ of the sporadic cancers. In sporadic colorectal cancers, loss of APC function in targeting $\beta$-catenin for its degradation is thought to account for most of the alterations in $\beta$-catenin expression $(4,7,29-31)$. APC mutation and loss of heterozygosity on $5 \mathrm{q}$ are frequent and early events in sporadic colorectal carcinogenesis (19, 32-38). Loss of APC expression as detected by immunohistochemistry or Western blot analysis is seen in 50 to $80 \%$ of sporadic colorectal tumors $(39,40)$. The role of APC in UC-related carcinogenesis is controversial. There is evidence of frequent loss of heterozygosity at 5q in UC-related cancers and dysplasias, and the APC protein was found to be truncated in 40 to $50 \%$ of a small series of UC-related cancers $(19,36,41-43)$. However, APC mutations within the mutational cluster region appear to be infrequent in UC-related neoplasia $(44,45)$.

A strong link was seen between alterations in APC and $\beta$-catenin expression in the sporadic tumors. However, the link between APC and $\beta$-catenin expression was not as clear in the UC-related cases. This may suggest that APC is not as important in regulating the cytoplasmic and nuclear $\beta$-catenin pool or that there are parallel pathways involved in UC-related cancers that contribute to altered $\beta$-catenin expression.

In summary, despite their origin in an inflammatory field, UC-related cancers show alterations in the expression of $\beta$-catenin, E-cadherin, and APC that are similar to those seen in sporadic cancers. However, differences in the staining patterns between the two tumor groups suggest that E-cadherin is more important in regulating $\beta$-catenin expression in UC-related cancers, 
whereas APC seems to be more important in sporadic cancers.

Acknowledgments: This research was supported by National Institutes of Health Grant CA 74826 and Deutsche Forschungsgemeinschaft Grant Au 141/1-1.

\section{REFERENCES}

1. Takayama T, Shiozaki H, Doki Y, Oka H, Inoue M, Yamamoto $\mathrm{M}$, et al. Aberrant expression and phosphorylation of betacatenin in human colorectal cancer. Br J Cancer 1998;77: 605-13.

2. Hiscox S, Jiang WG. Expression of E-cadherin, alpha, beta and gamma-catenin in human colorectal cancer. Anticancer Res 1997;17:1349-54.

3. He TC, Sparks AB, Rago C, Hermeking H, Zawel L, da Costa LT, et al. Identification of c-MYC as a target of the APC pathway. Science 1998;281:1509-12.

4. Sparks AB, Morin PJ, Vogelstein B, Kinzler KW. Mutational analysis of the APC/beta-catenin/Tcf pathway in colorectal cancer. Cancer Res 1998;58:1130-4.

5. Gumbiner BM. Carcinogenesis: a balance between betacatenin and APC. Curr Biol 1997;7:R443-6.

6. Barth AI, Nathke IS, Nelson WJ. Cadherins, catenins and APC protein: interplay between cytoskeletal complexes and signaling pathways. Curr Opin Cell Biol 1997;9:683-90.

7. Munemitsu S, Albert I, Souza B, Rubinfeld B, Polakis P. Regulation of intracellular beta-catenin levels by the adenomatous polyposis coli (APC) tumor-suppressor protein. Proc Natl Acad Sci U S A 1995;92:3046-50.

8. Nakamura T, Hamada F, Ishidate T, Anai K, Kawahara K, Toyoshima K, et al. Axin, an inhibitor of the Wnt signalling pathway, interacts with beta-catenin, GSK-3beta and APC and reduces the beta-catenin level. Genes Cells 1998;3:395403.

9. Dihlmann S, Amler LC, Schwab M, Wenzel A. Variations in the expression of the adenomatous polyposis coli (APC) tumor suppressor gene in human cancer cell lines of different tissue origin. Oncol Res 1997;9:119-27.

10. Ilyas M, Tomlinson IP, Rowan A, Pignatelli M, Bodmer WF. Beta-catenin mutations in cell lines established from human colorectal cancers. Proc Natl Acad Sci U S A 1997;94: 10330-4.

11. Brabletz T, Jung A, Hermann K, Gunther K, Hohenberger W, Kirchner T. Nuclear overexpression of the oncoprotein betacatenin in colorectal cancer is localized predominantly at the invasion front. Pathol Res Pract 1998;194:701-4.

12. Valizadeh A, Karayiannakis AJ, el-Hariry I, Kmiot W, Pignatelli M. Expression of E-cadherin-associated molecules (alpha-, beta-, and gamma-catenins and p120) in colorectal polyps. Am J Pathol 1997;150:1977-84.

13. Jankowski JA, Bruton R, Shepherd N, Sanders DS. Cadherin and catenin biology represent a global mechanism for epithelial cancer progression. Mol Pathol 1997;50:289-90.

14. Ilyas M, Tomlinson IP, Hanby A, Talbot IC, Bodmer WF. Allele loss, replication errors and loss of expression of E-cadherin in colorectal cancers. Gut 1997;40:654-9.

15. Karayiannakis AJ, Syrigos KN, Efstathiou J, Valizadeh A, Noda M, Playford RJ, et al. Expression of catenins and E-cadherin during epithelial restitution in inflammatory bowel disease. J Pathol 1998;185:413-8.

16. Jankowski JA, Bedford FK, Boulton RA, Cruickshank N, Hall C, Elder J, et al. Alterations in classical cadherins associated with progression in ulcerative and Crohn's colitis. Lab Invest 1998;78:1155-67.
17. Fleming ID, American Joint Committee on Cancer, American Cancer Society, American College of Surgeons, editors. AJCC cancer staging manual. 5th ed. Philadelphia: LippincottRaven; 1997.

18. Rubinfeld B, Souza B, Albert I, Munemitsu S, Polakis P. The APC protein and E-cadherin form similar but independent complexes with alpha-catenin, beta-catenin, and plakoglobin. J Biol Chem 1995;270:5549-55.

19. Tomlinson I, Ilyas M, Johnson V, Davies A, Clark G, Talbot I, et al. A comparison of the genetic pathways involved in the pathogenesis of three types of colorectal cancer. J Pathol 1998;184:148-52.

20. Gunther K, Brabletz T, Kraus C, Dworak O, Reymond MA, Jung A, et al. Predictive value of nuclear beta-catenin expression for the occurrence of distant metastases in rectal cancer. Dis Colon Rectum 1998;41:1256-61.

21. Dorudi S, Sheffield JP, Poulsom R, Northover JM, Hart IR. E-cadherin expression in colorectal cancer. An immunocytochemical and in situ hybridization study. Am J Pathol 1993;142:981-6.

22. Gofuku J, Shiozaki H, Tsujinaka T, Inoue M, Tamura S, Doki $\mathrm{Y}$, et al. Expression of E-cadherin and alpha-catenin in patients with colorectal carcinoma. Correlation with cancer invasion and metastasis. Am J Clin Pathol 1999;111:29-37.

23. Graff JR, Greenberg VE, Herman JG, Westra WH, Boghaert $\mathrm{ER}$, Ain KB, et al. Distinct patterns of E-cadherin CpG island methylation in papillary, follicular, Hurthle's cell, and poorly differentiated human thyroid carcinoma. Cancer Res 1998; 58:2063-6.

24. Saito Y, Takazawa H, Uzawa K, Tanzawa H, Sato K. Reduced expression of E-cadherin in oral squamous cell carcinoma: relationship with DNA methylation of $5^{\prime} \mathrm{CpG}$ island. Int J Oncol 1998;12:293-8.

25. Kanai Y, Ushijima S, Hui AM, Ochiai A, Tsuda H, Sakamoto $\mathrm{M}$, et al. The E-cadherin gene is silenced by CpG methylation in human hepatocellular carcinomas. Int J Cancer 1997;71: $355-9$.

26. Graff JR, Herman JG, Lapidus RG, Chopra H, Xu R, Jarrard $\mathrm{DF}$, et al. E-cadherin expression is silenced by DNA hypermethylation in human breast and prostate carcinomas. Cancer Res 1995;55:5195-9.

27. Yoshiura K, Kanai Y, Ochiai A, Shimoyama Y, Sugimura T, Hirohashi S. Silencing of the E-cadherin invasionsuppressor gene by CpG methylation in human carcinomas. Proc Natl Acad Sci U S A 1995;92:7416-9.

28. Nawrocki B, Polette M, Van Hengel J, Tournier JM, Van Roy F, Birembault P. Cytoplasmic redistribution of E-cadherincatenin adhesion complex is associated with downregulated tyrosine phosphorylation of E-cadherin in human bronchopulmonary carcinomas. Am J Pathol 1998;153:152130.

29. Polakis P. The adenomatous polyposis coli (APC) tumor suppressor. Biochim Biophys Acta 1997;1332:F127-47.

30. Rubinfeld B, Albert I, Porfiri E, Munemitsu S, Polakis P. Loss of beta-catenin regulation by the APC tumor suppressor protein correlates with loss of structure due to common somatic mutations of the gene. Cancer Res 1997;57:4624-30.

31. Polakis P. Mutations in the APC gene and their implications for protein structure and function. Curr Opin Genet Dev 1995;5:66-71.

32. Powell SM, Zilz N, Beazer-Barclay Y, Bryan TM, Hamilton SR, Thibodeau SN, et al. APC mutations occur early during colorectal tumorigenesis. Nature 1992;359:235-7.

33. Vogelstein B, Fearon ER, Hamilton SR, Kern SE, Preisinger $\mathrm{AC}$, Leppert $\mathrm{M}$, et al. Genetic alterations during colorectaltumor development. N Engl J Med 1988;319:525-32.

34. Kern DE, Fearon ER, Tersmette KWF, Enterline JP, Leppert $\mathrm{M}$, Nakamura Y, et al. Allelic loss in colorectal carcinoma. JAMA 1989;261:3099-103. 
35. Fearon ER, Vogelstein B. A genetic model for colorectal tumorigenesis. Cell 1990;61:759-67.

36. Fogt F, Vortmeyer AO, Goldman H, Giordano TJ, Merino MJ, Zhuang Z. Comparison of genetic alterations in colonic adenoma and ulcerative colitis-associated dysplasia and carcinoma. Hum Pathol 1998;29:131-6.

37. Gerdes H, Chen Q, Elahi AH, Sircar A, Goldberg E, Winawer D, et al. Recurrent deletions involving chromosomes 1, 5, 17, and 18 in colorectal carcinoma: possible role in biological and clinical behavior of tumors. Anticancer Res 1995;15:13-24.

38. Allen JI. Molecular biology of colon polyps and colon cancer. Semin Surg Oncol 1995;11:399-405.

39. Akehi S, Murao S, Ueda N, Okujima M, Magaribuchi T, Saheki S, et al. Immunohistochemical detection of truncated APC protein in sporadic human colorectal adenomas and adenocarcinomas. Virchows Arch 1996;429:21-6.

40. Smith KJ, Johnson KA, Bryan TM, Hill DE, Markowitz S, Willson JK, et al. The APC gene product in normal and tumor cells. Proc Natl Acad Sci U S A 1993;90:2846-50.
41. Greenwald BD, Harpaz N, Yin J, Huang Y, Tong Y, Brown VL, et al. Loss of heterozygosity affecting the p53, Rb, and mcc/ apc tumor suppressor gene loci in dysplastic and cancerous ulcerative colitis. Cancer Res 1992;52:741-5.

42. Kern SE, Redston M, Seymour AB, Caldas C, Powell SM, Kornacki S, et al. Molecular genetic profiles of colitisassociated neoplasms. Gastroenterology 1994;107:420-8.

43. Redston MS, Papadopoulos N, Caldas C, Kinzler KW, Kern SE. Common occurrence of APC and K-ras gene mutations in the spectrum of colitis-associated neoplasias. Gastroenterology 1995;108:383-92.

44. Wada M, Miller CW, Yokota J, Lee E, Mizoguchi H, Koeffler HP. Molecular analysis of the adenomatous polyposis coli gene in sarcomas, hematological malignancies and noncolonic, neoplastic tissues. J Mol Med 1997;75:139-44.

45. Tarmin L, Yin J, Harpaz N, Kozam M, Noordzij J, Antonio LB, et al. Adenomatous polyposis coli gene mutations in ulcerative colitis-associated dysplasias and cancers versus sporadic colon neoplasms. Cancer Res 1995;55:2035-8. 